\title{
Mangifera indica as propolis source: what exactly do bees collect?
}

\author{
Milena Popova' ${ }^{1}$ Boryana Trusheva', Nia llieva' ${ }^{1}$ Le Nguyen Thanh², Nguyen Thi Phuong Lien ${ }^{3}$ and \\ Vassya Bankova ${ }^{1 *}$ (D)
}

\begin{abstract}
Objective: The mango tree Mangifera indica is known as one of the botanical sources of propolis in Tropical regions. There are two different materials which bees can collect from a mango tree to produce propolis: the resin of the tree bark, and the latex found on the fruits. We performed the study of the chemical profile of mango resin in comparison with propolis in order to clarify its importance as propolis source.

Results: We compared the chemical profiles (by GC-MS analysis of ethanol extracts after silylation) of the resin and samples of propolis: of stingless bees (3 Vietnames, 2 Indonesian), and one of Apis mellifera from Thailand. In the resin and all propolis samples, 25 compounds were identified: fatty acids, cardanols (alk(en)yl phenols), cardols, anacardic acids, triterpene alcohols and ketones, cycloartane type triterpenic acids. All samples have the same qualitative composition but there are important quantitative differences. Considering literature data on mango latex, we conclude that bees of different species, make use of the two propolis sources offered by mango: bark resin and fruit latex, in different proportions. We also confirmed for the first time the presence of alk(en)yl phenols and anacardic acids in the tree bark resin of mango.
\end{abstract}

Keywords: Propolis, Stingless bees, Apis mellifera, Mangifera indica, Resin, Latex

\section{Introduction}

The mango tree Mangifera indica $\mathrm{L}$. has been recognized as propolis botanical source in 2005 [1]. There are communications reporting propolis of both European honey bees Apis mellifera and stingles bees Meliponini, originating from mango trees in numerous tropical countries in Africa [2, 3], the Americas [4-6], Southeast Asia [7-9], and even Oceania [10]. These reports are based on the identification of mango chemical markers in the corresponding propolis samples. There are two structural groups of such markers: the cycloartane type triterpenes cycloartenol, mangiferolic, isomangiferolic, and ambolic

\footnotetext{
*Correspondence: Vassya.Bankova@orgchm.bas.bg

${ }^{1}$ Institute of Organic Chemistry with Centre of Phytochemistry, Bulgarian

Academy of Sciences, Sofia, Bulgaria

Full list of author information is available at the end of the article
}

acids; and the group of phenolic lipids, mainly cardols (alk(en)yl resorcinols) [11, 12].

Studying propolis, some authors have found the abovementioned cycloartanes (but not any phenolic lipids), and based on these findings they concluded that Mangifera indica L. was the main plant source of the studied samples $[1,8,13,14]$. Others have identified only the cardols, no cycloartane acids, and made the same conclusion $[4,15]$. In these cases, the respective compounds have been isolated, purified and identified by spectral methods. A third group of studies, which have applied chemical profiling by hyphenated techniques, report the identification of both groups of markers [2, 7, 9]. It turns out that mango propolis contains cycloartanes, as well as phenolic lipids.

Obviously, the source plant of this propolis type is confirmed to be $M$. indica beyond doubt. However, there are two different materials which bees can collect from 
a mango tree in order to produce propolis: the reddishbrown resin which appears on the tree bark, and the latex found on the fruits. Both materials have been chemically studied. The resin has been found to contain triterpenes, mainly cycloartanes [13], and cardols have also been reported [4]. The latex, on the other hand, contains monoterpenes with typical raw mango aroma $[16,17]$, cardols [18-20], carbohydrates, and small amounts of proteins $[21,22]$. No triterpenes have been detected in latex, although several detailed studies have been carried out. So, we studied the chemical profile of mango resin in order to clarify its importance as propolis source.

\section{Main text \\ Methods}

\section{Sample collection}

Resin sample was collected in Mai Chau village, Hoa Binh province, designated as sample 1. Details on propolis samples are presented in Table 1.

\section{Sample preparation and GC-MS analysis}

The resin sample 1 and crude propolis samples $2-4$ were extracted with $70 \%$ ethanol $(1: 10, \mathrm{w} / \mathrm{v})$ at room temperature for $24 \mathrm{~h}$ ( 2 times). After evaporation in vacuo, the dry extracts were silylated: about $5 \mathrm{mg}$ dry extract was mixed with $50 \mu \mathrm{L}$ of dry pyridine and $75 \mu \mathrm{L}$ of N,Obis(trimethylsilyl)trifluoroacetamide (BSTFA). The GCMS analysis was performed with Hewlett-Packard 5890 series II Plus, linked to a Hewlett-Packard 5972 mass spectrometer system equipped with a $30 \mathrm{~m}$ DB-17HT capillary column, $0.25 \mathrm{~mm}$ i.d., $0.15 \mu \mathrm{m}$ film thickness. The temperature program from 100 to $320^{\circ} \mathrm{C}$ at a rate of $5{ }^{\circ} \mathrm{C} / \mathrm{min}$; carrier gas Helium at a flow rate of $0.8 \mathrm{~mL} / \mathrm{min}$. The split ratio was $75: 1$, the injector temperature $300{ }^{\circ} \mathrm{C}$, and the ionization voltage $70 \mathrm{eV}$.

\section{Compound identification and quantitation}

The compounds identification was accomplished using commercial libraries, literature data, and/or comparison with mass spectra and retention times of reference

Table 1 Propolis samples

\begin{tabular}{lll}
\hline Sample & Geographical origin & Bee species \\
\hline 2 & Da Nang, Vietnam & Lisotrigona cacciae \\
3 & Daklak, Vietnam & Lisotrigona cacciae \\
4 & Hoa Binh, Vietnam & Lepidotrigona ventralis \\
5 & Banten province, Indonesia $^{a}$ & Tetragonula laeviceps \\
6 & South Kalimantan Province, Indonesia $^{a}$ & Heterotrigona itama \\
7 & Phrae, Northern Thailand $^{b}$ & Apis mellifera L.
\end{tabular}

a Data from [23]

${ }^{\mathrm{b}}$ Data from [9]
Table 2 Compounds identified in all studied samples

\begin{tabular}{|c|c|}
\hline Compound type & Compound \\
\hline \multicolumn{2}{|l|}{ Fatty acids } \\
\hline & Palmitic acid \\
\hline & Stearic acid \\
\hline \multicolumn{2}{|c|}{ Cardanols (alk(en)yl phenols) } \\
\hline & Cardanol $\mathrm{C}_{15: 0}$ \\
\hline & Cardanol $\mathrm{C}_{15: 1}$ \\
\hline & Cardanol $\mathrm{C}_{17: 0}$ \\
\hline & Cardanol $\mathrm{C}_{17: 1}$ \\
\hline & Cardanol $\mathrm{C}_{\text {17:1 }}$ (isomer) \\
\hline & Cardanol $\mathrm{C}_{19: 1}$ \\
\hline \multicolumn{2}{|c|}{ Cardols (alk(en)yl resorcinols) } \\
\hline & Resorcinol $C_{15: 0}$ \\
\hline & Resorcinol $C_{17: 0}$ \\
\hline & Resorcinol $C_{17: 1}$ \\
\hline & Resorcinol $C_{19: 1}$ \\
\hline \multicolumn{2}{|l|}{ Anacardic acids } \\
\hline & Anacardic acid $C_{19: 0}$ \\
\hline & Anacardic acid $C_{19: 1}$ \\
\hline \multicolumn{2}{|c|}{ Triterpenic alcohols and ketones } \\
\hline & Lanosterol \\
\hline & $\beta$-Amyrin \\
\hline & Cycloartenol \\
\hline & a-Amyrin \\
\hline & Lupeol \\
\hline & $\beta$-Amyrenone \\
\hline & a-Amyrenone \\
\hline & Lupenone \\
\hline \multicolumn{2}{|c|}{ Cycloartane type triterpenic acids } \\
\hline & Mangiferolic acid \\
\hline & Ambolic acid \\
\hline & Isomangiferolic acid \\
\hline
\end{tabular}

compounds. The amounts of components of the propolis extracts were determined by considering their areas as the percentage of the total ion current. The ion currents generated depend on the characteristics of the compound and for this reason are regarded semiquantitative but allow comparison between samples.

\section{Results and discussion}

In order to clarify the role of mango tree bark resin as propolis source, we compared the chemical profiles (by GC-MS analysis of ethanol extract after silylation) of the resin and three samples stingless bees propolis from Vietnam. In the resin, 25 compounds were identified: 2 fatty acids, 6 cardanols (alk(en)yl phenols), 4 cardols (alk(en) yl resorcinols), 2 anacardic acids, 8 triterpene alcohols and ketones, and 3 cycloartane type triterpenic acids 


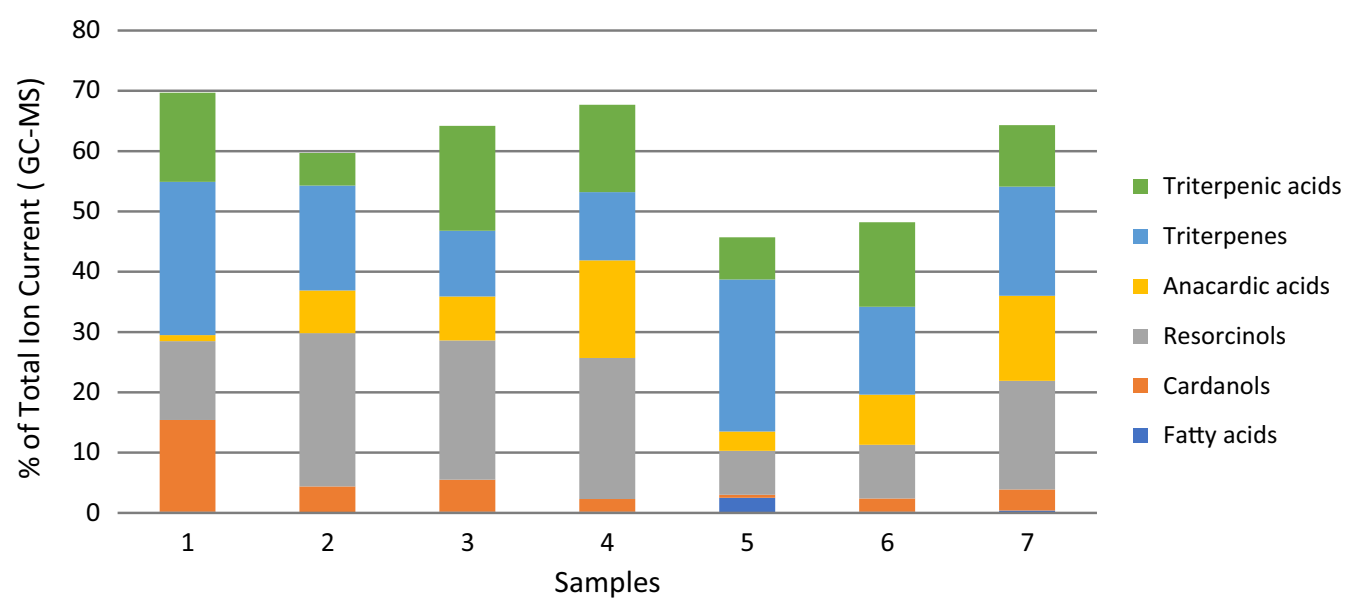

Fig. 1 Chemical profiles of the studied resin and propolis samples

(Table 2). All these compounds were present in the Vietnamese stingless bees propolis samples. In all samples, the main cardanols were heptadecenyl and nonadecenyl phenol; major cardol was heptadecenyl resorcinol, and most abundant triterpenes were cycloartenol, mangiferolic and isomangiferolic acid. The results of the GC-MS analysis are represented on Fig. 1 for the abovementioned 6 groups of compounds.

The results were compared with our data from earlier studies of Indonesian stingless bees propolis [23] and Thai A. mellifera propolis [9], classified as Mangifera type. The same 25 constituents have been identified in these samples, too. The quantitative data of these samples for the respective compound groups are also displayed in Fig. 1.

It is important to note that cardanols and anacardic acids were found in mango tree bark resin for the first time in our study. The resin, and propolis of different bee species and different locations have the same qualitative composition. However, there are quantitative differences and especially in the ratio phenolic lipids/triterpenes $(\mathrm{PL} / \mathrm{TT})$. This ratio is higher than $1(1.2-1.6)$ in the three Vietnamese propolis samples and the Thai $A$. mellifera propolis. It is however 0.7 for the resin, and 0.5 and 0.7 for the Indonesian propolis. It is noteworthy that the Vietnamese propolis samples come from three distinct regions of the country but are similar in their profiles, and differ quantitatively from the resin profile. On the other hand, Indonesian samples are closer to the mango resin profile, although the resin was collected in Vietnam. One possible explanation could be the collection by bees of both the available mango exudates: the tree bark resin and the fruit latex, depending on their availability and bees' preferences. In cases where the latex prevails, ratio
$\mathrm{PL} / \mathrm{TT}>1$ can be observed, while where $\mathrm{PL} / \mathrm{TT}<1$ more resin than latex has been foraged by bees.

In conclusion, our study demonstrates that bees of different species, including stingless and $A$. mellifera bees, can make use of the two propolis sources offered by Mangifera indica, bark resin and fruit latex, in different proportions. We also confirmed for the first time the presence of alk(en)yl phenols and anacardic acids in the tree bark resin of mango.

\section{Limitations of the study}

The mango resin sample was not collected in the vicinity of the bees' nests. Another limitation is the lack of mango latex for comparative study.

\section{Abbreviations}

BSTFA N: O-bis(trimethylsilyl)trifluoroacetamide; GC-MS: Gas chromatograpymass spectrometry; PL: Phenolic lipids; TT: Triterpenes.

\section{Acknowledgements}

The authors are thankful to Assoc. Prof. Daniela Antonova, PhD for running the GCMS analyses.

\section{Authors' contributions}

Conceptualization, VB and MP; methodology, MP; investigation, NI, BT, MP; resources, LNT, NTPL; writing —original draft preparation, VB; writing—review and editing MP, LNT, BT; project administration, VB. All authors have read and approved the fial manuscript.

\section{Funding}

The study was funded by Bulgarian Academy of Sciences and Vietnamese Academy of Science and Technology through a bilateral project, Code Number QTBG01.01/20-21.

\section{Availability of data and materials}

The dataset of the current study is available from the corresponding author on reasonable request. 


\section{Declarations}

Ethics approval and consent to participate

Not applicable.

\section{Consent to publish}

Not applicable.

\section{Competing interests}

The authors declare that they have no competing interests.

\section{Author details}

${ }^{1}$ Institute of Organic Chemistry with Centre of Phytochemistry, Bulgarian Academy of Sciences, Sofia, Bulgaria. ${ }^{2}$ Institute of Marine Biochemistry and Graduate University of Science and Technology, Vietnam Academy of Science and Technology, Hanoi, Vietnam. ${ }^{3}$ Institute of Ecology and Biological Resources, Vietnam Academy of Science and Technology, Hanoi, Vietnam.

Received: 16 October 2021 Accepted: 26 November 2021

Published online: 13 December 2021

\section{References}

1. Silva MDSSD, Citó AMDGL, Chaves MH, Lopes JAD. Cycloartane triterpenoids of propolis from Teresina-PI. Qum Nova. 2005;28(5):801-4. https:// doi.org/10.1590/S0100-40422005000500013.

2. Kardar MN, Zhang T, Coxon GD, Watson DG, Fearnley J, Seidel V. Characterisation of triterpenes and new phenolic lipids in Cameroonian propolis. Phytochemistry. 2014;106:156-63. https://doi.org/10.1016/j. phytochem.2014.07.016.

3. Popova M, Dimitrova R, Al-Lawati HT, Tsvetkova I, Najdenski H, Bankova V. Omani propolis: chemical profiling, antibacterial activity and new propolis plant sources. Chem Cent J. 2013;7(1):1-8.

4. Herrera-López MG, Rubio-Hernández El, Richomme P, Schinkovitz A, Calvo-Irabién LM, Rodríguez LMP. Resorcinolic lipids from Yucatecan propolis. J Braz Chem Soc. 2020;31:186-92. https://doi.org/10.21577/ 0103-5053.20190156.

5. Gallardo DG, Fajardo M, Alonso YN, Echemendía LSM, Copello JM Physical-chemical characterization and thin layer chromatographic comparison of a local propolis with the Mangifera indica resin. Pharm Biosci J. 2020;8(1):15-21. https://doi.org/10.20510/ukjpb/8/i1/1581041940.

6. Nina N, Quispe C, Jiménez-Aspee F, Theoduloz C, Giménez A, SchmedaHirschmann G. Chemical profiling and antioxidant activity of Bolivian propolis. J Sci Food Agric. 2016;96(6):2142-53. https://doi.org/10.1002/ jsfa.7330.

7. Trusheva B, Popova M, Koendhori EB, Tsvetkova I, Naydenski C, Bankova V. Indonesian propolis: chemical composition, biological activity and botanical origin. Nat Prod Res. 2011;25(6):606-13. https://doi.org/10. 1080/14786419.2010.488235.

8. Pujirahayu N, Suzuki T, Katayama T. Cycloartane-type triterpenes and botanical origin of propolis of stingless Indonesian bee Tetragonula sapiens. Plants. 2019;8(3):57. https://doi.org/10.3390/plants8030057.

9. Sanpa S, Popova M, Tunkasiri T, Eitssayeam S, Bankova V, Chantawannakul P. Chemical profiles and antimicrobial activities of Thai propolis collected from Apis mellifera. Chiang Mai J Sci. 2017;44:438-48.

10. Trusheva B, Stancheva K, Gajbhiye N, Dimitrova R, Popova M, Saraf R, Bankova V. Two new prenylated stilbenes with an irregular sesquiterpenyl side chain from propolis from Fiji Islands. Rec Nat Prod. 2016;10(4):465.

11. Escobedo-Martínez C, Concepción Lozada M, Hernández-Ortega S, Villarreal ML, Gnecco D, Enríquez RG, Reynolds W. ${ }^{1} \mathrm{H}$ and ${ }^{13} \mathrm{C}$ NMR characterization of new cycloartane triterpenes from Mangifera indica. Magn Reson Chem. 2012;50(1):52-7. https://doi.org/10.1002/mrc.2836.

12. Ediriweera MK, Tennekoon KH, Samarakoon SR. A review on ethnopharmacological applications, pharmacological activities, and bioactive compounds of Mangifera indica (Mango). Evid Based Complement Alternat Med. 2017;2017: 6949835. https://doi.org/10.1155/2017/6949835.

13. Li F, Awale S, Zhang H, Tezuka Y, Esumi H, Kadota S. Chemical constituents of propolis from Myanmar and their preferential cytotoxicity against a human pancreatic cancer cell line. J Nat Prod. 2009;72(7):1283-7. https:// doi.org/10.1021/np9002433.

14. Nguyen HX, Nguyen MT, Nguyen NT, Awale S. Chemical constituents of propolis from Vietnamese Trigona minor and their antiausterity activity against the PANC-1 human pancreatic cancer cell line. J Nat Prod. 2017;80(8):2345-52. https://doi.org/10.1021/acs.jnatprod.7b00375.

15. Negri G, Silva CCF, Coelho GR, Nascimento RMD, Mendonça RZ. Cardanols detected in non-polar propolis extracts from Scaptotrigona aff. postica (Hymenoptera, Apidae, Meliponini). Braz J Food Technol. 2019;22:e2018265. https://doi.org/10.1590/1981-6723.26518.

16. Musharraf SG, Uddin J, Siddiqui AJ, Akram MI. Quantification of aroma constituents of mango sap from different Pakistan mango cultivars using gas chromatography triple quadrupole mass spectrometry. Food Chem. 2016;196:1355-60. https://doi.org/10.1016/j.foodchem.2015.10.040.

17. John KS, Rao LJM, Bhat SG, Rao UP. Characterization of aroma components of sap from different Indian mango varieties. Phytochemistry. 1999;52(5):891-4

18. Bandyopadhyay C, Gholap AS, Mamdapur VR. Characterization of alkylresorcinol in mango (Mangifera indica L.) latex. J Agric Food Chem. 1985;33:377-9. https://doi.org/10.1021/jf00063a014.

19. Kumpoun W, Uthaibutra J, Boonyakiat D. Antifungal compound content in mango latex at different maturity stages. Acta Hortic. 2008;804:303-8. https://doi.org/10.17660/ActaHortic.2008.804.42.

20. Hassan MK, Irving DE, Dann EK, Coates LM, Hofman PJ. Sap properties and alk (en) ylresorcinol concentrations in Australian-grown mangoes. Ann Appl Biol. 2009;154(3):419-27. https://doi.org/10.1111/j.1744-7348. 2008.00313.x

21. John KS, Bhat SG, Rao UP. Biochemical characterization of sap (latex) of a few Indian mango varieties. Phytochemistry. 2003;62(1):13-9. https://doi. org/10.1016/S0031-9422(02)00441-7.

22. Karunanayake KOLC. A qualitative analysis of mango (Mangifera indica L.) latex and anatomy of latex canals. J Sci. 2019;10(2):11-20. https://doi.org/ 10.4038/jsc.v10i2.21.

23. Fikri AM, Popova M, Sulaeman A, Bankova V. Stingless bees and Mangifera indica: a close relationship? Indian J Nat Prod Resour. 2020;11(2):130-4.

\section{Publisher's Note}

Springer Nature remains neutral with regard to jurisdictional claims in published maps and institutional affiliations.

Ready to submit your research? Choose BMC and benefit from:

- fast, convenient online submission

- thorough peer review by experienced researchers in your field

- rapid publication on acceptance

- support for research data, including large and complex data types

- gold Open Access which fosters wider collaboration and increased citations

- maximum visibility for your research: over 100M website views per year

At BMC, research is always in progress.

Learn more biomedcentral.com/submissions 